\title{
Probiotics and Lactose Intolerance
}

\author{
Roel J. Vonk, Gerlof A.R. Reckman, \\ Hermie J.M. Harmsen and Marion G. Priebe
}

Additional information is available at the end of the chapter

http://dx.doi.org/10.5772/51424

\section{Introduction}

Lactose is the main sugar in milk and therefore the main energy source for the newborn. Milk contains $4,8 \%$ lactose [1]. Lactose is a disaccharide consisting out of glucose and galactose.

In normal physiological conditions lactose is hydrolyzed by lactase also known as lactasephlorizin hydrolase and under its systemic name lactose- galactosehydrolase (EC 3.2.1.108), which is a brush-border membrane bound enzyme. Glucose and galactose are taken up by the intestinal cells and transported into the bloodstream (Fig. 1). A considerable part of glucose and most galactose is cleared by the liver after the first pass. Lactose which is not hydrolyzed in the small intestine is passing into the colon where it is fermented. Lactose itself and its metabolites are osmotic active products causing an osmotic pressure; excessive amounts present in the colon are related to the development of clinical symptoms as diarrhea.

The apparent lactase enzyme activity is affected by various factors like a. age, b. genetic background, c. integrity of the small intestinal membrane and d. the small-intestinal transit time

a. The activity of the enzyme lactase is age dependent. The activity is high in the first year of age and declines until adulthood is reached. It is not clear what the physiological advantage is of the age dependency of the lactase activity in relation to the disaccharide glucose-galactose.

Several remarkable aspects can be brought up in this respect:

- Galactose has a higher hepatic clearance than glucose, which prevents a significant postprandial increase in blood glucose in the systemic circulation.

- Galactose does not lead to an induction of the pancreatic insulin response. 
- Lactase might have a variable and limited capacity which leads to a regulated spill over of lactose into the colon. There lactose might act as a primer (prebiotic) for the colonic microbiota in the first period of life (See also the subchapter of colonic fermentation of lactose).

b. The role of the genetic background of the lactase activity has been described in detail elsewhere [2].

c. The lactase activity is strongly affected by the integrity of the small intestinal membrane. This is the reason why in patients with celiac disease, which have not been treated optimally, symptoms of lactose intolerance may appear [3].

d. Finally, the turnover of lactose by the enzyme is dependent on the small intestinal transit time (apparent enzyme activity).

Fermented milk products can alleviate symptoms by delaying gastric emptying, orocecal transit time, or both. Delay of gastric emptying is due to the higher viscosity of the fermented milk product as compared to milk. Decrease of orocecal transit time is due to the metabolic products of probiotics or a lower osmotic force due to improved lactose digestion. A longer passage time in lactose maldigesters aids in hydrolyzing as much lactose as possible before spill over into the colon occurs. These findings support that pasteurized yogurt already provides alleviation of symptoms and that yogurt containing living probiotics improves this alleviation [4]. The effect of sugars, including lactose, on the small intestinal transit time is not well documented [5]. Changes in intestinal transit time due to the sugar molecules might especially play a role in other pathological conditions like irritable bowel disease.

Lactose intolerance is the pathophysiological situation in which the small intestinal digestion and / or colonic fermentation is altered which leads to clinical symptoms.

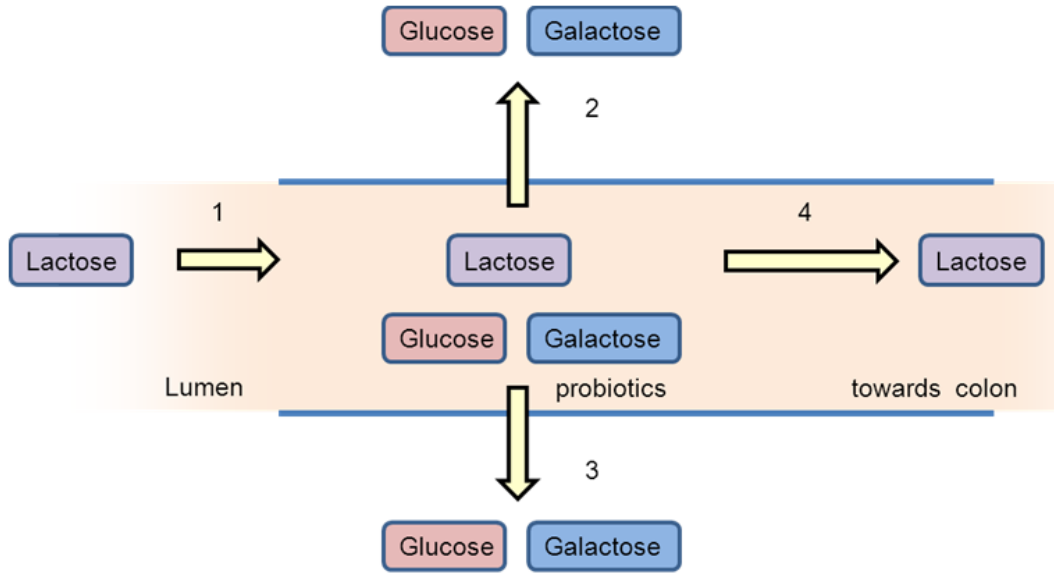

Figure 1. Small intestinal metabolism of lactose. Lactose enters the small intestine (1), lactose is then coverted by lactase from the host (2) or by probiotics (3). Excess amounts of lactose spill over into the colon (4). 


\section{Colonic fermentation of lactose}

Lactose which is spilled over into the colon can be hydrolyzed by the colonic bacterial enzyme $\beta$-galactosidase resulting in the formation of glucose and galactose. Glucose and galactose are subsequently converted into lactate as well as into the short chain fatty acids (SCFA) acetate, propionate and butyrate (see Fig. 2). Additionally, microbial biomass will be formed. The original substrate lactose, the intermediate products glucose and galactose and the final products can all contribute to the osmotic load in the colon. This might lead to increased colonic transit time, altered fermentation profiles and ultimately to diarrhea.

The central question is which molecule contributes most to the pathological symptoms, like diarrhea: the original substrate lactose and / or one of the metabolites.

As indicated in Fig. 2 the number of molecules is doubled after the first conversion by $\beta$ galactosidase and tripled after the second conversion. A rapid conversion to the final metabolites enhances the osmotic force considerable.

We first analyzed the role of lactose itself assuming that $\beta$-galactosidase is the rate limiting step. In a recent paper of us [6], we describe that inducing the colonic $\beta$-galactosidase by administration of yogurt and additional probiotics alleviates the clinical symptoms of lactose intolerance in an adult Chinese population. This suggests a specific role of lactose itself in the development of clinical symptoms. Our observation was confirmed by [7], who observed in post-weaning Balb/c mice that symptoms of diarrhea were reduced by inducing the $\beta$-galactosidase activity by administration of a recombinant Lactococcus lactis MG1363/FGZW strain expressing $\beta$-galactosidase.

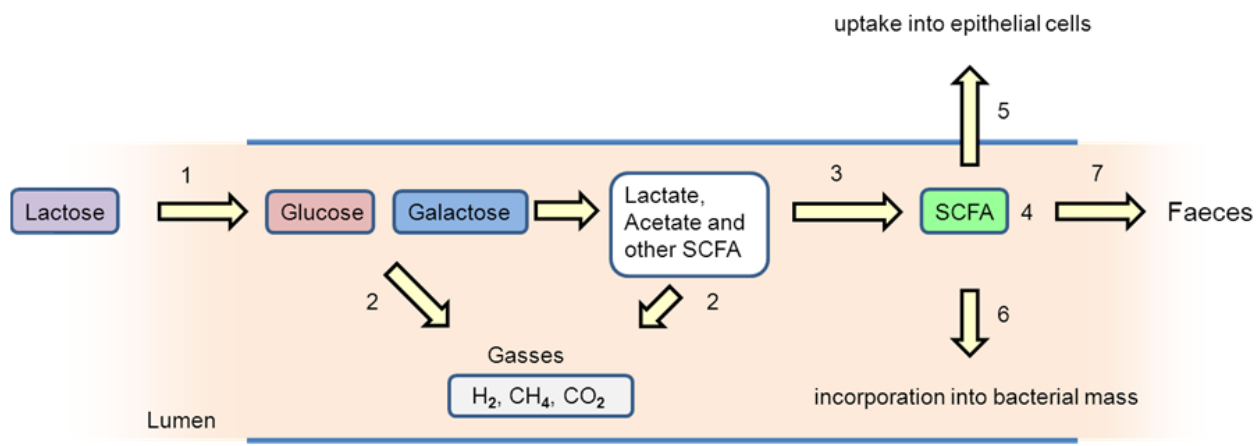

Figure 2. Colonic metabolism of lactose. Lactose enters the colon (1) and is fermented by the microbiota into glucose and galactose. Gasses such as hydrogen, methane and carbondioxide are formed (2). Lactate is also formed and converted into short chain fatty acids (SCFA)(3,4), also in this stage gasses are formed (2). These SCFAs can be taken up by epithelial cells (5) or can be used by the microbiota (6) or excreted in the faeces (7). 
In contrast with these observations is the fact that $\beta$-galactosidase is an abundant enzyme in the colonic microbiota. It is present in many phylogroups of bacteria which in total might contribute to more than $40 \%$ of the total population of the colonic microbiome (Table 1 ). However, relative abundance and composition of bacteria with $\beta$-galactosidase in the distal colon do not seem to be related to lactose intolerance [8]. Another argument to consider is that the conversion of lactose into glucose, galactose and subsequently SCFA / lactate doubles and triples respectively the osmotic pressure. This aspect will be discussed in more detail under the chapter administration of pre- and probiotics.

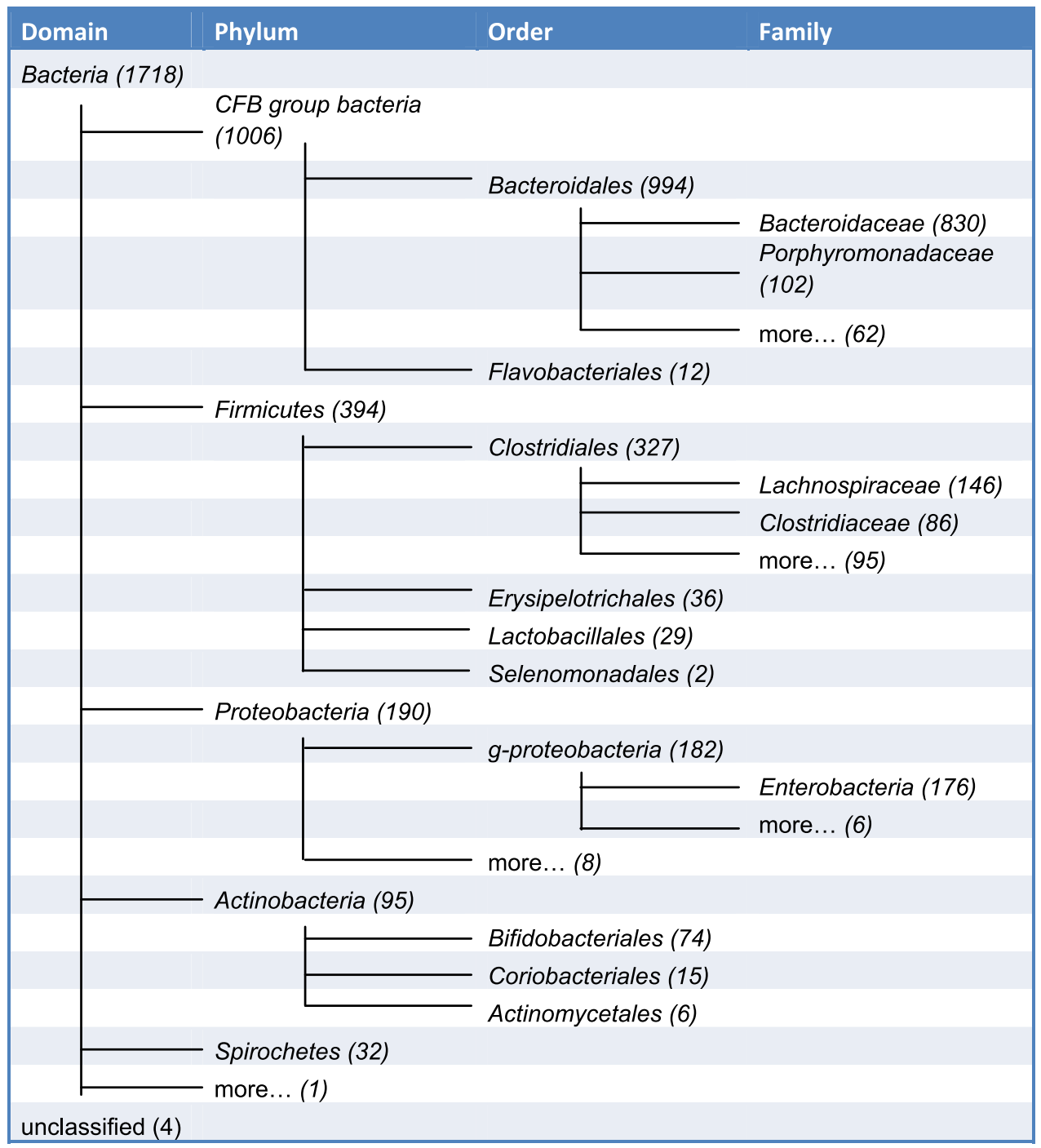

Table 1. Overview of all bacteria known to produce $\beta$-galactosidase. 
Considering the physiological aspects of lactose digestion and fermentation it is clear that sufficient small intestinal hydrolysis of lactose related to the dose consumed will prevent symptoms of lactose intolerance. In case of relative insufficient lactase activity in the small intestine, spillover into the colon will occur. Adequate removal of osmotic active molecules, however, can prevent development of clinical symptoms of diarrhea.

\section{Clinical symptoms of lactose intolerance}

Symptoms of intestinal discomfort, abdominal pain and / or diarrhea can occur in case of lactose intolerance. These complaints are, however, not specific and can also be noticed in several other clinical conditions (for example irritable bowel syndrome, coeliac disease, Crohn's disease). For proper treatment and correct interpretation of interventions accurate diagnosis of the underlying pathophysiology is therefore very important.

\section{Diagnostics of lactose intolerance}

The most direct diagnosis is the analysis of lactase activity. However, the enzyme activity derived from a small intestinal biopsy does not reflect the overall lactase activity in the small intestine because of the patchy character of the distribution of this enzyme. This can lead to false positive and negative estimation of the overall physiological capacity to hydrolyze lactose.

Screening the genotype of people with lactose intolerant-like symptoms can aid in the correct diagnosis of lactose intolerance. The lactase gene can contain single-nucleotide polymorphisms (SNP) in the promotor region which leads to a high capacity to digest lactose. The most common SNP C/T-13910 is found in many Northwest European people. Several methods have been developed to detect this most common SNP. Järvelä et al. [2] sum up in their review the different methods for detection: minisequencing, enzyme digest, polymerase chain reaction-restriction fragment length polymorphism and pyrosequencing. For detection of all known SNPs, sequencing is the most reliable technique. Because there is a poor correlation between abdominal symptoms and lactase activity, genetics alone is not sufficient for a correct clinical diagnosis of adult lactose intolerance.

For congenital lactase deficiency genetic screening is effective, mutations occur in the lactase gene itself and symptoms start shortly after birth [2]. The prevalence of this syndrome however, is very low.

The analysis of the capacity to digest lactose in vivo by using two stable isotopes might be theoretically the best diagnostical method [9]. This test consists of the administration of ${ }^{13} \mathrm{C}$ lactose and ${ }^{2} \mathrm{H}$-glucose and calculation of the ratio of the ${ }^{13} \mathrm{C}$-glucose $/{ }^{2} \mathrm{H}$-glucose concentrations measured in plasma. This test can be used to analyze the effect of interventions and to demonstrate changes in the capacity to digest lactose. However, as a routinely used diagnostic tool this test is not applicable because of its complex character. 
The most commonly used diagnostic method for lactose intolerance is the hydrogen breath test. This test is easy to apply in clinical practice, but as discussed in detail by us [12] others [11] this test leads to false positive and false negative results.

A way to improve the precision of the breath test is to use ${ }^{13} \mathrm{C}$-lactose as a substrate and measure both $\mathrm{H}_{2}$ and ${ }^{13} \mathrm{CO}_{2}$ in breath as first described by Hiele et al. [12]. This might be the best applicable test in daily practice.

\section{Application of pre- and probiotics to improve the clinical symptoms of lactose intolerance}

An effect of an intervention with probiotics can be expected at two levels:

a. hydrolysis of lactose in the milk product and in the small intestine

b. at the level of colonic fermentation

a. The hydrolytic capacity of probiotic strains can be used to reduce the actual amount of lactose in the product, as occurs in yogurt. It can also be used to increase the overall hydrolytic capacity in the small intestine. The probiotic strain can be alive or can be lysed in the intestinal tract for its effect. Lactobacillus acidophilus is a bile-salt tolerant bacterium which hardly increases lactose digestion. However, sonication of Lactobacillus Acidophilus milk weakens their membranes and improves lactoseintolerance symptoms [4]. Lactobacillus delbrüeckii in a milk product can deliver $\beta$ galactosidase activity. These microorganisms do not have to be alive as long as their membranes are intact which helps to protect $\beta$-galactosidase during gastric passage [4]. Yogurt improves the lactose intolerance due to the presence of a group of lactobacillus bacteria it contains, i.e., Lactobacillus acidophilus [13]. Kinova et al. [14] described the beneficial effects of Lactobacillus present in fermented milk products. In [15] is described that consumption of yogurt containing Lactobacillus bulgaricus and Streptococcus thermophiles alleviate the lactose intolerance through their enzyme lactase when the product reaches the intestinal tract. Also Masood et al. [16] describe the beneficial effects of lactic acid bacteria in their review. From these findings it is inferred that lactose intolerance can be reduced by regularly consuming the fermented dairy products due to the production of $\beta$-galactosidase enzyme by lactic acid bacteria present in them.

In general, it can be stated that in yogurt several probiotic strains are present which results in a better tolerance of lactose in lactose intolerant persons.

b. Application of probiotics to manipulate the colonic fermentation.

As suggested before [17], one of the problems in studies concerning this topic is that it is difficult to prove that the intervention only has an effect at the level of the colon and not at the level of the small intestine. 
As discussed before it is not clear which compound, lactose or one of its fermentation metabolites contributes most to the development of symptoms of lactose intolerance. The hypothesis is that removal of these product(s) can reduce the clinical symptoms.

\section{Removal of lactose}

Lactose is hydrolyzed by $\beta$-galactosidase. We recently published [6] that a mix of probiotics in yogurt together with Bifidobacterium longum capsules could increase the $\beta$-galactosidase activity in faeces and alleviate the complaints of lactose intolerance.

Together with the observation that the capacity to digest lactose, which was measured by the 13C-lactose/2H-glucose test, was not changed, it could be concluded that this intervention has an effect on colonic metabolism, possibly by enhancing the $\beta$-galactosidase activity. A study with mice [7] suggested the same mechanism. However, after analyzing the presence of $\beta$-galactosidase in the common bacterial strains in humans it can be concluded that $\beta$-galactosidase is abundantly present and it seems that administration of exogenous $\beta$-galactosidase from probiotics is not important. Alleviation of complaints and enhanced $\beta$-galactosidase concentration in stool therefore might have been a coincidence in our study.

\section{Removal of glucose and galactose}

Glucose is a preferred substrate for many bacterial strains and it is not likely that enhanced glucose removal by probiotic administration might play a role in alleviation of symptoms. Also galactose is easily consumed by most bacteria. Our in vitro studies [18] also indicated that accumulation of glucose and galactose does not occur during the breakdown of lactose, which confirms that these molecules once formed are subsequently metabolized very fast.

3. Removal of acetate, propionate, butyrate and lactate

As illustrated in Fig. 2 removal of SCFA takes place at the epithelium by uptake in the colonocytes and through the uptake and metabolism by various bacteria ("bacterial mass").

Uptake of SCFA into the epithelial cells is very effective because of co-transport of fluid which reduces the osmotic force [19]. The maximal epithelial uptake rate is not known and it is not known if this varies in persons with hypolactasia with and without symptoms after lactose consumption.

Another major way by which SCFA are removed is via the uptake and metabolism by bacteria. SCFA serve as a carbon and energy source for the anaerobic bacteria and this may increase the "bacterial mass". In the presence of sulphate, lactate may be metabolized by sulphate-reducing bacteria, producing toxic sulphide as byproduct [20]. On the other hand lactate together with acetate can be converted by different groups of bacteria into butyrate; for instance by bacteria such as Eubacterium hallii and Anaerostipes cacca [21]. Butyrate is 
thought to be beneficial for colonic health. Also Bacteroides several subspecies are capable of metabolizing lactate, but produce propionate. The metabolism of intermediates like lactate and acetate are an important step in the breakdown of sugars by gut bacteria [22]. For gut health it is important that from lactate a balanced mixture of SCFA are formed and for this correct conditions should be present. The hypothesis that for the prevention of diabetes type 1 butyrate production is preferred over propionate production is stated by [23]. They stated this because butyrate production enforces the barrier function of the gut. Therefore, conditions that stimulates these metabolic associations should be enforced. This implies that a mixture of pro- and prebiotics as occurs in yogurt might be an efficient approach, since it favors acetate and lactate formation, and in this way stimulate butyrate formation. If lactate removal via for instance butyrate production, does not occur this may impact functioning of the epithelium. It then can be speculated that an impaired epithelial function will hamper the uptake of lactate, and causes an increased osmotic pressure in the gut.

Several other studies have reported the beneficial effect of a probiotic intervention on symptoms of lactose intolerance but without describing a precise mechanism. In some of these studies the observation that the specific strains under study survive the small intestinal passage is used as an argument that the effect occurs at the colonic level.

The combination of Lactobacillus casei Shirota and Bifidobacterium breve Yakult has been shown to survive gastrointestinal transit and to improve symptoms of lactose intolerance. This effect persists after the intervention is ceased [24]. Other probiotic strains have shown beneficial effects on lactose digestion and symptoms in lactase deficient persons [12,25,26]. Further investigation with different strains of bifidobacteria or lactobacilli on symptoms of lactose intolerance showed contradictory results. [27] observed that 7 day supplementation with Lactobacillus acidophilus did not change hydrogen production or symptoms. [28] however found a decrease in hydrogen production after 7 days of milk intake supplemented with Lactobacillus acidophilus, but not all individuals had relief of their symptoms. Bifidobacterium breve for 5 days did not improve lactose intolerance symptoms, but reduction in breath hydrogen was measured [29]. Overall these contradictions have not led to a general acceptance of probiotics as a efficient treatment for lactose intolerance [30-32].

The observation of adaptation seen in lactose intolerant persons consuming regularly small amounts of dairy products might be in accordance with the concept of adaptation of the colonic metabolism by increased lactate metabolizing populations in the gut. This allows efficient metabolism of increased amounts of lactose [33]. The observation that lactulose fermentation is impaired during ingestion of ampicillin ( $2 \mathrm{~g} /$ day) gives rise to the idea that antibiotics can disrupt the microbiota in the colon. There is no evidence in the literature that antibiotics have a negative effect on the fermentation of lactose, however it would not be surprising if such a phenomenon was found [34]. 


\section{Conclusion}

There is evidence that probiotics can alleviate symptoms of lactose intolerance. This can occur by increased hydrolysis of lactose in the dairy product and in the small intestine. It can also be achieved by manipulation of the colonic metabolism. However, the precise mechanism how colonic metabolism influences lactose intolerance symptoms is not yet known. The reported studies are not consistent in their experimental set-up, results and conclusions.

The diagnosis of lactose maldigestion and the relation to complaints is highly complex. For an effective treatment of lactose intolerance and a correct interpretation of the effects of an intervention, knowledge of the underlying mechanisms of lactose intolerance is essential. Development of new strategies concerning the treatment with probiotics should therefore include an analysis of the relevant intermediate endpoints. In this way applications of probiotics for treatment of lactose intolerance could lead to a promising strategy.

\section{Author details}

Roel J. Vonk *, Gerlof A.R. Reckman, Hermie J.M. Harmsen and Marion G. Priebe Dept. of Cell Biology, Centre for Medical Biomics and Dept. of Medical Microbiology, UMCG, Groningen, The Netherlands

\section{References}

[1] Chandan R. Dairy-based ingredients. Eagan Press, St. Paul, MN; 1997.

[2] Järvelä I, Torniainen S, Kolho K. Molecular Genetics of Human Lactase Deficiencies. Annals of Medicine 2009;41 568-575.

[3] Koetse HA, Vonk RJ, Gonera-De Jong GBC, Priebe MG, Antoine JM, Stellaard F, Sauer PJJ. Low Lactase Activity in a Small-Bowel Biopsy Specimen: Should Dietary Lactose Intake Be Restricted in Children with Small Intestinal Mucosal Damage? Scandinavian Journal of Gastroenterology 2006;41(1) 37-41.

[4] de Vrese M, Stegelmann A, Richter B, Fenselau S, Laue C, Schrezenmeir J. ProbioticsCompensation for Lactase Insufficiency. The American Journal of Clinical Nutrition 2001;73(suppl) 421S-429S.

[5] He T, Priebe MG, Welling GW, Vonk RJ. Effect of Lactose on Oro-Cecal Transit in Lactose Digesters and Maldigesters. European Journal of Clinical Investigation 2006;36(10) 737-742.

[6] He T, Priebe MG, Zhong Y, Huang C, Harmsen HJM, Raangs GC, Antoine JM, Welling GW, Vonk RJ. Effects of Yogurt and Bifidobacteria Supplementation on the Colonic Microbiota in Lactose-Intolerant Subjects. Journal of Applied Microbiology 2008;104 595-604.

\footnotetext{
${ }^{*}$ Corresponding Author
} 
[7] Li J, Zhang W, Wang C, Yu Q, Dai R, Pei X. Lactococcus Lactis Expressing Foodgrade $\beta$-galatosidase Alleviates Lactose Intolerance Symptoms in Post-weaning Balb/c Mice. Applied Microbiology and Biotechnology 2012;DOI 10.1007/s00253012-3977-4.

[8] He T, Priebe MG, Vonk RJ, Welling GW. Identification of Bacteria with $\beta$-galactosidase Activity in Faeces from Lactas Non-Persistent Subjects. FEMS Microbiology Ecology 2005;54(3) 463-469.

[9] Vonk RJ, Stellaard F, Priebe MG, Koetse HA, Hagedoorn RE, De Bruijn S, Elzinga H, Lenoir-Wijnkoop I, Antoine J-M. The 13C/2H-glucose Test for Determination of Small Intestinal Lactase Activity. European Journal of Clinical Investigation 2001;31(3) 226233.

[10] He T, Venema K, Priebe MG, Welling GW, Brummer R-JM, Vonk RJ. The Role of Colonic Metabolism in Lactose Intolerance. European Journal of Clinical Investigation 2008;38(8) 541-547.

[11] Ojetti V, LaMura R, Zocco MA, Cesaro P, De Masi E, La Mazza A, Cammarota G, Gasbarrini G, Gasbarrini A. Quick Test: New Test for the Diagnosis of Duodenal Hypolactasia. Digestive Diseases and Sciences. 2008;53(6) 1589-1592.

[12] Hiele M, Ghoos Y, Rutgeerts P, Vantrappen G, Carchon H, Eggermont E. 13CO2 Breath Test Using Naturally 13C-Enriched Lactose for Detection of Lactase Deficiency in Patients with Gastrointestinal Symptoms. Journal of Laboratory and Clinical Medicine 1988;122(2) 193-200.

[13] Fuller R. Probiotics in Human Medicine. Gut 1991;32 439-442.

[14] Kinová Sepová H, Bilková A, Bukovský M. Lactobacilli and their Probiotic Properties. Ceska Slov Farm. 2008;57(2) 95-98.

[15] Schaafsma G. Lactose Intolerance and Consumption of Cultured Dairy Products - a Review. International Dairy Federation Newsletter 1993;2 15-16.

[16] Masood MI, Qadir MI, Shirazi JH, Khan IU. Beneficical Effects on Lactic Acid Bacteria on Human Beings. Critical Reviews in Microbiology 2011;37(1) 91-98.

[17] Priebe MG, Vonk RJ, Sun X, He T, Harmsen HJM, Welling GW. The Physiology of Colonic Metabolism. Possibilities for Interventions with Pre- and Probiotics. European Journal of Nutrition 2002;41(s1) 2-10.

[18] He T, Priebe MG, Harmsen HJM, Stellaard F, Sun X, Welling GW, Vonk RJ. Colonic Fermentation May Play a Role in Lactose Intolerance in Humans. The Journal of Nutrition 2006;136(1) 58-63.

[19] Binder HJ. Role of Colonic Short-Chain Fatty Acid Transport in Diarrhea. Annual Review of Physiology 2010;72 297-313.

[20] Marquet P, Duncan SH, Chassard C, Bernalier-Donadille A, Flint HJ. Lactate Has the Potential to Promote Hydrogen Sulphide Formation in the Human Colon. FEMS Microbiology Letters 2009;299(2) 128-134. 
[21] Muñoz-Tamayo R, Laroche B, Walter E, Doré J, Duncan SH, Flint HJ, Leclerc M. Kinetic Modelling of Lactate Utilization and Butyrate Production by Key Human Colonic Bacterial Species. FEMS Mircobiology Ecology 2011;76(3) 615-624.

[22] Flint HJ, Bayer EA, Rincon MT, Lamed R, White BA. Polysaccharide Utilization by Gut Bacteria: Potential for New Insights from Genomic Analysis. Nature Reviews Microbiology. 2008;6(2) 121-31.

[23] Brown CT, Davis-Richardson AG, Giongo A, Gano KA, Crabb DB, Mukherjee N, Casella G, Drew JC, Ilonen J, Knip M, Hyöty H, Veijola R, Simell T, Simell O, Neu J, Wasserfall CH, Schatz D, Atkinson MA, Triplett EW. Gut Microbiome Metagenomics Analysis Suggests a Functional Model for the Development of Autoimmunity for Type 1 Diabetes. PLoS ONE. 2011;6(10) e25792.

[24] Almeida CC, Lorena SLS, Pavan CR, Akasaka HMI, Mesquita MA. Beneficial Effects on Long-Term Consumption of a Probiotic Combination of Lactobacillus casei Shirota and Bifidobacterium breve Yakult May Persist After Suspension of Therapy in LactoseIntolerant Patients. Nutrition in Clinical Practice 2012;27(2) 247-251.

[25] Lin M-Y, Dipalma JA, Martini MC, Gross CJ, Harlander SK, Savaiano DA. Comparative Effects of Exogenous Lactase ( $\beta$-galactosidase) Preparations on in Vivo Lactose Digestion. Digestive Diseases and Sciences 1993;38(11) 2022-2027.

[26] Rabot S, Rafter J, Rijkers GT, Watzl B, Antoine J-M. Guidance for Substantiating the Evidence for Beneficial Effects of Probiotics: Impact of Probiotics on Digestive System Metabolism. Journal of Nutrition 2010;140(3) 677S-689S.

[27] Saltzman JR, Russell RM, Golner B, Barakat S, Dallal GE, Goldin BR. A Randomized Trial of Lactobacillus acidophilus BG2FO4 to Treat Lactose Intolerance. The American Journal of Clinical Nutrition. 1999;69(1) 140-146.

[28] Kim HS, Gilliland SE. Lactobacillus acidophilus as a Dietary Adjunct for Milk to Aid Lactose Digestion in Humans. Journal of Dairy Science 1983;66 959-966.

[29] Park MJ, Lee JH, Kim KA, Kim JS, Jung HC, Song IS, Kim CY. The Changes in the Breath Hydrogen Concentration After the Ingestion of Bifidobacterium breve KY-16 in the Lactose Malabsorbers. The Korean Journal of Gastroenterology. 1999;34(6) 741748.

[30] Levri KM, Ketvertis K, Deramo M, Merenstein JH, D'amico F. Do Probiotics Reduce Adult Lactose Intolerance? The Journal of Family Practice. 2005;54 613-620.

[31] Shaukat A, Levitt MD, Taylor BC, MacDonald R, Shamliyan TA, Kane RL, Wilt TJ. Systematic Review: Effective Management Strategies for Lactose Intolerance. Annals of Internal Medicine. 2010;152(12) 797-803.

[32] Wilt TJ, Shaukat A, Shamliyan T, Taylor BC, MacDonald R, Tacklind J, Rutks I, Schwarzenberg SJ, Kane RL, Levitt M. Lactose Intolerance and Health. Evidence Report - Technology Assesment 2010;192 1-410.

[33] Rong Q, Cheng Yu H, HuiZhang D, Guo Z, Ling LI, Sheng YE. Milk Consumption and Lactose Intolerance in Adults. Biomedical and Environmental Sciences 2011;24(5) 512517. 
[34] Rao SS, Edwards CA, Austen CJ, Bruce C, Read NW. Impaired Colonic Fermentation of Carbohydrate After Ampicillin. Gastroenterology 1988;94(4) 928-932. 